\title{
Opinion on Important Findings for the Diagnosis and Therapy in Clinical Medicine
}

\section{Felix-Martin Werner*}

Higher Vocational School of Elderly Care and Occupational Therapy, Euro Academy Pößneck, Pößneck, Thuringia, 07381, Germany

This issue contents basic research and with important findings for the diagnosis and therapy of different diseases seen in clinical medicine, In the research article: Bone Marrow Derived Mesenchymal Stem Cell Therapy in Induced Acute Renal Injury in Adult Male Albino Rats by Abd Elwahab et al. [1] the authors induced acute renal failure in rats by clamping the renal pedicles for $40 \mathrm{~min}$. They divided the experimental animals into four groups and treated two groups, in the third group by a local injection of mesenchymal stem cells and in the fourth group with a systemic injection of mesenchymal stem cells. The first group was the control group, and the second group was not treated. The most important result of the research article was that a systemic injection of mesenchymal stem cells restored renal function better than a local injection. This offers a possibility to introduce a new treatment of acute renal failure. In the case report: Inflammatory Pseudotumor of the Spleen: A Case Report, Anand [2] describes the case of a female patient with an inflammatory pseudotumor of the spleen with splenomegalie and fever. The only diagnostic and therapeutic procedure is splenectomy and the histological diagnosis of the tumor.

In the case report Percutaneous Injection of Polymethyl Methacrylate for the Treatment of Osteoarthritic Knee Pain Caused by Bone Marrow Edema: A Case Report and Review of Literature by Gao LH [3] the authors describe the case of osteoarthritis in the knees with a bone marrow edema. As a therapeutic option, polymethyl methacrylate was injected percutaneously. This therapy can replace a joint replacement.

In the case report Primary Vaginal Invasive Squamous Cell Carcinoma: A Rare Case Report by Santosh T et al. [4] the authors describe a 62 -year old female patient with a primary vaginal invasive squamous cell carcinoma, where the cervix was not enroled. The appropriate diagnosis was very important, and the convenient therapy was radiotherapy.

In the research article Spermatocyte Spreading during Meiotic Cell Preparation is a Two Step Process by Muhtadi [5] the authors show via video microscopy that spreading of meiotic cells has an optimal concentration of the dilute detergent solution and occurs in two phases.

In the research article The Role of Combined Nicotine and Caffeine Administration on the Histological Structure of the Rat Urinary Bladder with a Special Reference to P53 by Allehaibi et al. [6] the authors show in an animal experiment the effect of the combined administration of nicotine and caffeine on the urinary bladder mucosa. The authors examine the erosion of the urinary bladder mucosa after combined nicotine and caffeine administration by histological techniques.

In the short communication: Shall we sample every pancreatic mass? By Frossard JL [7], the author discusses by giving a case report the question whether every pancreatic mass, which in $15 \%$ of the cases has another diagnosis than adenocarcinoma, should be diagnosed by a fine needle aspiration.

In the research article The Impact of Extensive Cytoreductive Surgery for Ovarian Cancer on the Histopathology Laboratory Workload by El-Masry [8] the authors examine the histopathological laboratory workload, when standard therapy of the ovarian cancer is changed to an extensive cytoreductive therapy. This new cancer therapy which improves patients' prognosis augments the complexity and range of specimens and thus increases the laboratory workload.

In the case report - Three Cases of Major Depression: Different Pharmacological Options, the authors Werner and Covenas [9] describe a different severity of major depression in three cases, which require a totally different pharmacological treatment. The authors already reported about a multimodal pharmcotherapy in major depression (J Cytol Histol 2014; 5: 4).

Case reports and research in this issue contents articles with basic research and with important findings for the diagnosis and therapy of different diseases are seen in clinical medicine.

\section{References}

1. Abd Elwahab SA, Hussein Ali A, Sayed Mahmoud A, Fathy Ahmed A, Fouad Ahmed R (2017) Bone Marrow Derived Mesenchymal Stem Cell Therapy in Induced Acute Renal Injury in Adult Male Albino Rats. J Cytol Histol 8: 451.

2. Anand K (2017) Inflammatory Pseudotumor of the Spleen: A Case Report. J Cytol Histol 8: 448.

3. Gao LH, Miao GQ Zang XH, Sun $\mathrm{H}$, Wang LH (2017) Percutaneous Injection of Polymethyl Methacrylate for the Treatment of Osteoarthritic Knee Pain Caused by Bone Marrow Edema: A Case Report and Review of Literature. J Cytol Histol 8: 452.

4. Santosh T, Sahu P, Manoj Kumar P, Bandana M (2017) Primary Vaginal Invasive Squamous Cell Carcinoma: A Rare Case Report. J Cytol Histol 8: 1000449.

5. Muhtadi R, Ahmed EA, Scherthan H (2017) Spermatocyte Spreading during Meiotic Cell Preparation is a Two Step Process . J Cytol Histol 8: 1000450.

6. Frossard JL (2017) Shall we Sample Every Pancreatic Mass? J Cytol Histol 8: 453.

7. Allehaibi Al, Abunasef SK, Zaki Al (2017) The Role of Combined Nicotine and Caffeine Administration on the Histological Structure of the Rat Urinary Bladder with a Special Reference to P53. J Cytol Histol 8: 455.

8. El-Masry A, El-Bahrawy M (2017) The Impact of Extensive Cytoreductive Surgery for Ovarian Cancer on the Histopathology Laboratory Workload. J Cytol Histol 8: 454.

9. Werner FM, Covenas R (2017) Three Cases of Major Depression: Different Pharmacological Antidepressant Options. J Cytol Histol 8: 457.

*Corresponding author: Werner FM, Medical Doctor, $\mathrm{Dr}$. Med, Research field: neural networks in neurological and psychiatric diseases University of Salamanca, Instituto de Neurociencias de Castilla y León (INCYL), Laboratorio de Neuroanatomía de los Sistemas Peptidérgicos (Lab. 14), c/ Pintor Fernando Gallego, 1, 37007-Salamanca, Spain, Tel: +34/923/29-44-00, extn. 1856; Fax: +34/923/29-45-49; E-mail: felixm-werner@versanet.de

Received June 15, 2017; Accepted June 22, 2017; Published June 30, 2017

Citation: Werner FM (2017) Opinion on Important Findings for the Diagnosis and Therapy in Clinical Medicine. J Cytol Histol 8: 461. doi: 10.4172/21577099.1000461

Copyright: (C) 2017 Werner FM. This is an open-access article distributed under the terms of the Creative Commons Attribution License, which permits unrestricted use, distribution, and reproduction in any medium, provided the original author and source are credited. 